\title{
Comprehensive principles of quantitative hydrogeology established by Darcy (1856) and Dupuit (1857)
}

\author{
Robert W. Ritzi Jr. ${ }^{1}$ and Patricia Bobeck ${ }^{2}$ \\ Received 14 March 2008; revised 22 June 2008; accepted 8 July 2008; published 3 October 2008.
}

[1] Henry Darcy and Jules Dupuit were born 1 year apart, were classmates during their undergraduate and graduate education in civil engineering, and were colleagues in the French corps of civil engineers, with overlapping appointments as inspector general in the early 1850s. At that time Darcy turned over, to Dupuit, his position as Director of Water and Bridges in Paris and the research on pipe flow he had begun there in 1849. In these pipe flow experiments, Darcy discovered what he referred to as a "law" of fluid mechanics, which is that above a certain velocity threshold, the head loss is proportional to velocity squared, and below that threshold, the head loss is linearly proportional to velocity. During the remainder of their careers, Darcy and Dupuit applied this law with their collective, extensive, prior knowledge of fluid mechanics, geology, aquifers, wells, and springs to quantitative studies of fluid flow in the subsurface (and also in pipes, aqueducts, rivers, and sand filters). Two monographs by Darcy (1856) and Dupuit (1857) are mutually cited retrospectives on much of this research, submitted at nearly the same time, to the same Corps des Ponts et Chaussées publisher, near the end of their careers. Between these two monographs, many of the fundamentals of quantitative hydrogeology were established, including the equation for groundwater motion, average linear velocity, average travel time, effective hydraulic conductivity for layered heterogeneity, conservation of mass in confined and unconfined flow, the nature of the regional pieziometric surface, porous flow versus flow through discrete fractures and karst conduits, the equation for a cone of depression around flowing wells, superposition of the effects of multiple wells, and capture zone geometries of wells within a regional flow field.

Citation: Ritzi, R. W., Jr., and P. Bobeck (2008), Comprehensive principles of quantitative hydrogeology established by Darcy (1856) and Dupuit (1857), Water Resour. Res., 44, W10402, doi:10.1029/2008WR007002.

\section{Introduction}

[2] In quantitative hydrogeology, the principles of fluid mechanics are combined with a geologic understanding of the occurrence and movement of groundwater. This combination allows quantification of important attributes such as volume flow rate, head loss, magnitude and direction of velocity, mass transport rate, and residence time in the subsurface.

[3] One paradigm for the history of quantitative hydrogeology is that it began with the introduction of an equation for fluid motion through sand, determined empirically by Henry Darcy's sand column experiments as described by Darcy [1856, Appendix D]. This thinking is clearly characterized by a statement by Freeze and Back [1983, p. 10]: "the experiments carried out by Darcy with the help of his assistant, Ritter, in Dijon, France in 1855 and 1856 represent the beginning of groundwater hydrology as a quantitative science."

[4] In their view, Darcy's sand column experiments were a scientific revolution. The revolution sparked a subsequent

\footnotetext{
${ }^{1}$ Department of Earth and Environmental Sciences, Wright State University, Dayton, Ohio, USA.

${ }^{2}$ Geotechnical Translations, Austin, Texas, USA.

Copyright 2008 by the American Geophysical Union. 0043-1397/08/2008WR007002\$09.00
}

period of evolution (cf. the Kuhnian model for science history) as Darcy's law was applied through the latter half of the nineteenth and early twentieth centuries by several European hydraulic engineers including Boussinesq, Dupuit, Forchheimer and the two Thiems. Freeze and Back [1983] view the next revolution as occurring 79 years later with Theis's [1935] introduction of transient well hydraulics. An understanding of who Henry Darcy was and how he conducted his sand column experiments first began to emerge in the English literature from Freeze's [1994] excellent scholarship and translations (from French) including Darcy's [1856] Appendix D. Freeze [1994] concluded "I'm sure that Darcy went to his grave without the realization that he had unlocked one of nature's basic laws," bringing into question Darcy's awareness of the significance of his sand filter experiments within the context of quantitative hydrogeology and well hydraulics. This conclusion, and the prevalent view of the beginnings of quantitative hydrogeology, were biased by the limited scope of what was translated, primarily Appendix D along with Darcy necrologies and nontechnical biographies. Accessing the historical documents and translating from the antiquated French terminology is difficult. The scope of Dupuit's contributions to quantitative hydrogeology had been similarly underrepresented.

[5] However, a newer wave of scholarship emerged coincident with the bicentennial commemorations of the 
births of Henry Philibert Gaspard Darcy (1803-1858) and Arsene Jules Etienne Dupuit (1804-1866). This work includes new reviews of their career contributions [Brown, 2002, 2004, 2003; Gisonni, 2003; Rat, 2003; Hager, 2004; Simmons, 2007], a new perspective on the discovery of Darcy's law [Brown 2002], and the complete English translation of Darcy [1856] by Bobeck [2004]. From this collective work, the paradigm for the history of quantitative hydrogeology shifts. Darcy's sand filter experiments confirmed a linear law of fluid mechanics which he had discovered in an earlier phase of his career. From the beginning of his career, Darcy had endeavored to quantify and understand attributes of groundwater flow to wells and springs, and Darcy [1856] clearly shows that he understood the significance of his linear law to well hydraulics (as discussed by Brown [2002]) and applied it in quantifying groundwater flow to artesian wells.

[6] In this new view, the "revolution" occurred earlier with the results of pipe flow experiments that Darcy began in Paris in 1849 , which continued in the early 1850 s with Dupuit. In these experiments, a basic law of fluid mechanics was discovered: head loss is proportional to velocity if velocity is below a threshold, and proportional to the square of velocity when the threshold is exceeded. In the remainder of their careers, Darcy and Dupuit applied this law to understanding pipe flow, sand filters, regional groundwater flow in aquifers, well hydraulics, spring flow, and open-channel flow.

[7] Darcy [1856] and Dupuit [1857] are mutually cited retrospectives, published near the end of their careers, both through their Corps des Ponts et Chaussées publisher. The thesis of this article is that a fairly comprehensive development of quantitative hydrogeology was created by these near-simultaneous publications of Darcy [1856] and Dupuit [1857]. To support this thesis, we review these documents together with a focus on the comprehensive application of fluid mechanics to the geologic understanding of groundwater flow.

[8] We will not repeat all of the biographical information, already somewhat redundant, in the collective body of prior literature cited above, but rather only the most relevant facts. These include the following.

[9] Darcy and Dupuit began university studies 1 year apart, and overlapped as classmates through most of their undergraduate and graduate education at Ecole Polytechnique and Ecole des Ponts et Chaussées, from 1822 to 1826. Their schooling included the very best of education in fluid mechanics, from instructors including Navier, Cauchy, Coriolis, Barre de Saint-Venant, and de Prony [Rouse and Ince, 1957; Freeze, 1994; Phillip, 1995; Brown, 2002, 2003; Hager, 2004].

[10] Their subsequent careers as civil engineers in the Corps des Ponts et Chaussées included developing public water utilities. At the time, the conventional focus was on developing municipal supplies from among three possible sources: springs, wells, or filtered river water. The principles of hydrodynamics in which they were schooled were applied ubiquitously to understanding all three of these potential sources of municipal supply, and to understanding municipal delivery systems including flow through pipes and aqueducts [Darcy, 1834, 1856, 1857; Dupuit, 1854, 1857, 1863]. For Darcy, the application began immediately. His first major public project was to find a public water supply for Dijon. All three potential sources were rigorously evaluated starting in the late 1820s. As he drilled and assessed flow versus head loss in an artesian well, and as he quantified spring flows via weirs, he assiduously assimilated the understanding and methodologies of the time, and he found ways to expand them through the rest of his career [Brown, 2002]. The understanding of groundwater and surface water contamination from surface sources came into awareness during Darcy's time, as discussed extensively by Darcy [1856], and further motivated the need to quantify attributes of groundwater flow.

[11] As reviewed by Brown [2002], the convention at the time of Darcy and Dupuit's education would have focused on hydrodynamic theory from the perspective of predicting head loss. They were taught the Bernoulli equation which results from conservation of energy along a streamline:

$$
h_{L}=\left(\frac{V_{2}^{2}}{2 g}+\frac{P_{2}}{\gamma}+z_{2}\right)-\left(\frac{V_{1}^{2}}{2 g}+\frac{P_{1}}{\gamma}+z_{1}\right)
$$

where $h_{L}$ is head loss, $V$ is velocity, $P$ is fluid pressure, $z$ is elevation, $g$ is gravitational acceleration, and $\gamma$ is specific weight. In the hydraulics of pipe flow, they were taught that head loss was given by de Prony's equation:

$$
h_{L}=\frac{L}{D}\left(a V+b V^{2}\right)
$$

where $L$ is length, $D$ is pipe diameter, and $a$ and $b$ are empirical coefficients of proportionality, and were as yet imperfectly known.

[12] The structural geology and stratigraphy of the regions in which Darcy worked were already well known in his time, as was the conceptual hydrogeology, and Darcy had a sophisticated understanding of that knowledge [Rat, 2003]. Darcy wrote using the conventional structural, petrologic, mineralogic and paleontological nomenclature of the time (including species names of fossils). He gave a solid scientific review of the hydrologic cycle, and of the karst springs emanating from the Jurassic limestone near Dijon, and discussed groundwater chemistry and the role of carbonic acid in controlling calcite solubility. Darcy's knowledge of the hydrogeology of the Paris basin is discussed further below; here we just take initial note of the fact that Darcy had appreciable knowledge of both geology and fluid mechanics to bring to bear on conceptualizing and quantifying aspects of groundwater processes.

[13] Darcy and Dupuit had overlapping appointments in Paris as Inspector Divisionnaire of the Corps des Ponts et Chaussées, and as Chief Director of Water and Pavements. Darcy was appointed on 16 June 1848 [Lochot, 2003]. Dupuit was called in May 1850 to be Darcy's successor, presumably because of Darcy's frail health [Caudemberg, 1858; Mahyer, 1866; Hager, 2003, 2004]. By this point in their careers, Darcy and Dupuit had both been awarded the Legion d'Honneur for their outstanding contributions to civil engineering. The French government was choosing the best of the Corps for its top administration. With these appointments came a hydraulic research facility at Chaillot. From August 1849 to October 1850, Darcy conducted the 
experiments which revealed the important linear law between fluid motion and its driving force that exists at low velocities (further elucidated later by Reynolds [1883]). According to Caudemberg [1858; see Hager, 2003, p. 59]: "Mr. Dupuit, who followed Mr. Darcy in the service of the streets and water of Paris, did not wait for the initiative of the administration to gracefully continue and facilitate his comrade's continued important experiments."

[14] This pipe flow work was published by Dupuit [1854] and by Darcy [1857, 1858] (publication dates are discussed further below). Darcy [1856, e.g., p. 93] frequently refers to the law (of fluid mechanics) he discovered, and writes equation (2) for pipe flow as, for water velocities above $10 \mathrm{~cm} / \mathrm{s}$

$$
h_{L}=\frac{L b}{\pi r^{5}} q^{2}
$$

The form for velocities below $10 \mathrm{~cm} / \mathrm{s}$ is

$$
h_{L}=\frac{L a}{\pi r^{4}} q
$$

where $r$ is radius and $q$ is the volume discharge rate.

[15] In 1855 Darcy, under failing health, was released from all appointments except research. This freedom enabled him to conduct experiments in Dijon on flow through porous media and through open channels. Dupuit remained in Paris, became central to the Huassmann metamorphosis of the city, and continued to publish on political economics and hydraulics. They were quite aware of the significance of each other's work during this time, as evidenced by the mutual cross citations in their publications on pipe flow, aquifer flow, and open channel flow. Indeed, as Inspectors Divisionnaires, they reviewed and reported on Corps projects throughout the country, in addition to the work of each other [Brown, 2002].

[16] We close this introduction with a final note of importance. The works of Darcy and Dupuit were not presented or published in chronological order. Darcy's revolutionary results at Chaillot were not published until 1857 (also 1858), but are extensively referred to and built upon by Darcy [1856]. The Darcy [1856] monograph in fact reviews previously unpublished, important work from the start of Darcy's career. It does not present knowledge in the order in which he acquired it. The monograph was primarily intended to be a guide to the practicing engineer developing new municipal water supplies, and is organized as such. Thus, while Appendix D presents the equation of fluid motion through sands, it is applied to quantitative hydrogeology much earlier in the monograph. Dupuit's work on quantitative hydrogeology was written at nearly the same time as Darcy's, and was submitted in 1857 to the Academy of Sciences as a paper for its Mémoires (more on this below). Though the review was favorable, Dupuit refused to make requested revisions, and chose instead to add it, as it was, as Dupuit [1863, chapter 8], but with an additional section responding to the principal issue raised by the Academy. Our perspective is that Darcy and Dupuit's work was done during essentially the same period of time, and we review their collective knowledge and contributions together, without further regard to chronology.

[17] In the following sections, we review Darcy and Dupuit's contributions to quantitative hydrogeology in sedimentary aquifers, well hydraulics, and spring flow in fractured and karst regimes. Because the English translation of Darcy [1856] by Bobeck [2004] and the work by Dupuit [1857] as reproduced by Dupuit [1863, chapter 8] are the most readily attained, we will give page numbers as in those documents.

\section{Quantifying Flow in Sedimentary Aquifers: Hydrogeology and Hydraulics of Artesian Wells}

[18] Darcy [1856, p. 122, note 56, and plate 22] reviewed the geologic structure of the Paris Basin and depicted it in cross section, as shown in Figure 1. A quintessential basin comprising Cretaceous and Jurassic sedimentary strata, it was used as an example in the geologic textbooks of Darcy's time [e.g., Lyell, 1834; Darcy, 1856, p. 78]. Darcy describes the conceptual hydrogeologic model, invoking the three-dimensional basin structure in relation to topography. Recharge occurs where formations are exposed at higher elevations around the basin rim (Figure 1). Where the entrenched valleys of the major rivers expose these formations at lower elevations, springs occur (see also Figure 7).

[19] The well on the left in Figure 1 represented the famous Grenelle artesian well in Paris, at the basin center (Figure 2). The Grenelle well drew from a Cretaceous sandstone formation that is confined by much thicker, low-permeability strata (as reflected in Darcy's cross section). The well at the right represented other artesian wells located out toward the basin margin, such as at Tours.

[20] Brown [2002] discussed that in Darcy and Dupuit's time, because of the expense and difficulty in drilling wells, monitoring wells did not exist. Thus, piezometric differences (head loss) in the aquifer away from an artesian well could not be measured, and hydrogeologic processes associated with flow to a well had to be deduced from singlewell experiments.

[21] Figure 3 has 10 plots that Darcy constructed from data collected in single-well experiments in which the elevation of the discharge orifice (the abscissa in the plots) of an artesian well was changed, and the resulting change in the volume rate of flow from the well (the ordinate in the plots) was quantified (Figure 4a). Darcy [1856, p. 93] asked why these plots are linear in each case and answered the question by applying his law of linear versus parabolic head loss, to differentiate between the head loss occurring because of groundwater flowing in the aquifers versus flow up the riser pipes. Darcy pointed out that groundwater generally circulates at velocities less than $10 \mathrm{~cm} / \mathrm{s}$ and so head loss in sands probably follows the linear law, whereas flow in the riser pipe occurs at velocities above $10 \mathrm{~cm} / \mathrm{s}$ and the head loss is probably parabolic.

[22] So that these respective head losses could be quantified, Darcy [1856, p. 94] superposed them in deriving the following formula (using his symbols):

$$
\left(h_{1}-h_{0}\right)+\left[\frac{b_{1}}{\pi^{2} r^{5}}\left(H_{1} q_{1}^{2}-H_{0} q_{0}^{2}\right)\right]=C\left(q_{0}-q_{1}\right)
$$




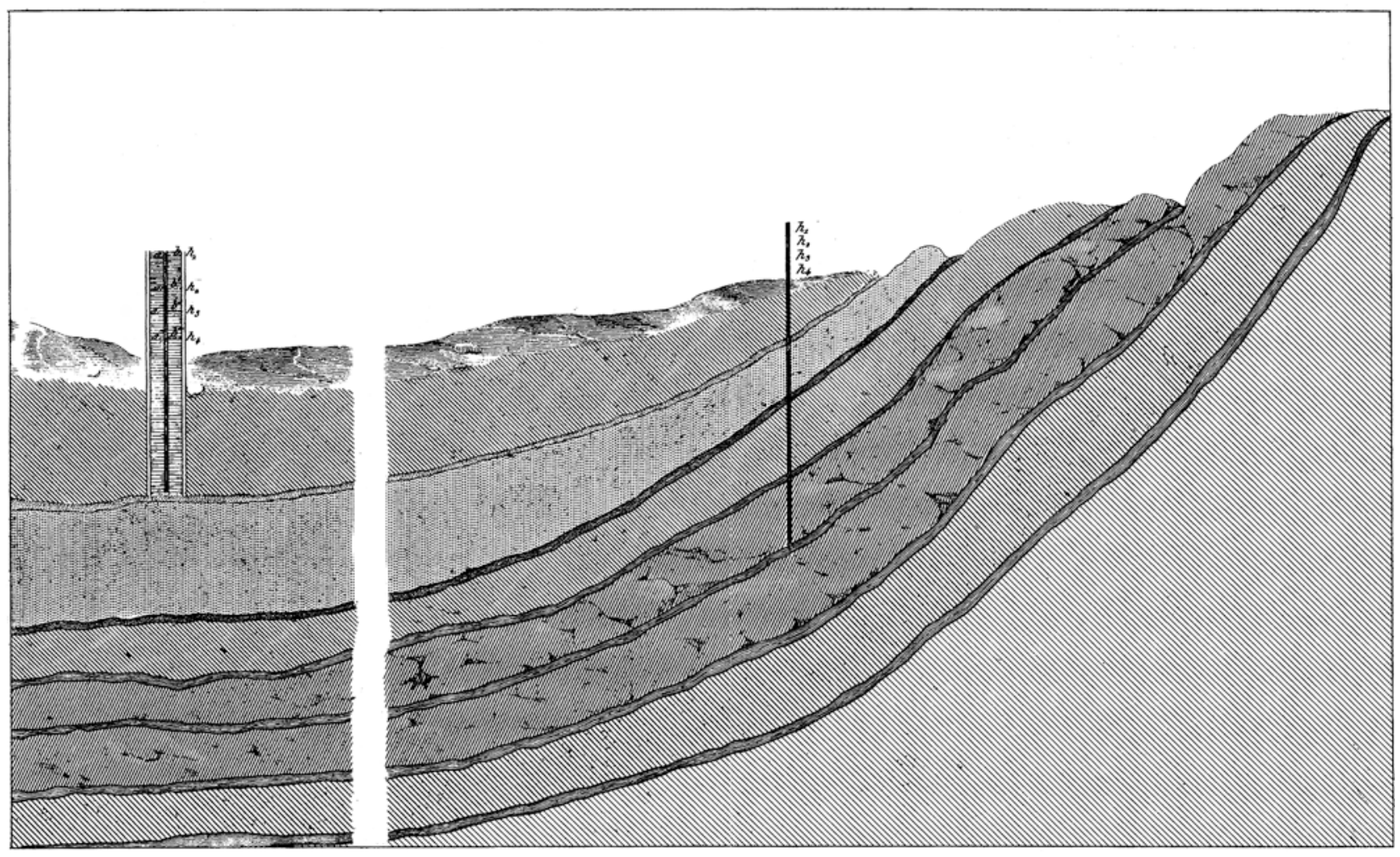

Figure 1. Stratigraphy and structural geology of the Paris basin [from Darcy, 1856]. The well on the left (representing the famous artesian well at Grenelle (Figure 2)) taps a Cretaceous sandstone (the "Greensand" in Darcy's time) that is interstratified with thicker chalk strata. The well on the right (representing artesian wells at Tours, $150 \mathrm{~km} \mathrm{SW}$ of Paris) taps a deeper Jurassic sandstone interstratified with vuggy limestone (“cornbrash" in Darcy's time).

where the " 0 " designates a higher discharge orifice elevation and " 1 " designates a lower elevation (see Figure $4 a$ ), $h$ is the aquifer pieziometric height measured from ground surface [Darcy, 1856, p. 90 , and p. 122, note 53], $H$ is the length of the riser pipe measured from the base of the well within the aquifer [Darcy, 1856, p. 91], $r$ is the riser pipe radius (Darcy [1856, p. 82 and p. 84]). As per Dupuit [1854], Darcy uses the harmonic mean for an effective radius when, as at Grenelle, the riser pipe varies in radius, and $C$ is a constant [Darcy, 1856, p. 94], considered further below.

[23] The formula is written consistent with the axes of the plots in Figure 3, and the first part of the left-hand side (LHS) is the difference in aquifer head loss at the well created by changing the elevation of the discharge orifice, and the second part is the difference in the well loss from flow up riser pipes of corresponding, different lengths.

[24] In presenting this equation, Darcy discussed the fact that if head loss was entirely due to flow up the riser pipe (as if the aquifer were infinite and capable of supplying flow $q$ to the well with no measurable aquifer head loss relative to prewell conditions) then the first term on the LHS disappears, and the plots in Figure 3 would be parabolic instead of linear. Dupuit [1857, Figure 71] plotted a representation of linear versus parabolic behavior as shown in Figure 5 (also see Figure 4b; the orientation and symbols are changed from Darcy's). In considering the lack of the parabolic behavior in the data plotted in Figure 3, Darcy [1856, p. 87] observed:

But for the most part, it is not like that [i.e., well loss in the riser pipe does not dominate, so parabolic behavior is not observed], and I will now consider the opposite limiting case, that is, where the artesian well encounters the impermeable ceiling of a [lower] sandy layer in which the [groundwater] has conditions analogous to that of water passing through a [sand] filter.

[25] Note that in the last phrase, Darcy makes a clear statement of the fact that flow through sand filters (as presented by Darcy [1856, Appendix D]) is analogous to flow through sedimentary aquifers. His focus at this point in the monograph is that seepage in aquifer sands occurs at low velocities, and in this case the second term on the LHS of equation (5) should disappear, giving the linear relationship indeed seen in the plots of Figure 3.

[26] Thus, Darcy has reciprocating references between this section of the monograph and the better known Appendix D, where he showed that head loss in low-velocity flow through sands indeed followed his linear law. The equation he wrote for fluid motion through sands, with the head loss between two points separated by a distance $l$, is [Darcy, 1856, p. 458]:

$$
q=k s \frac{h_{L}}{l}
$$




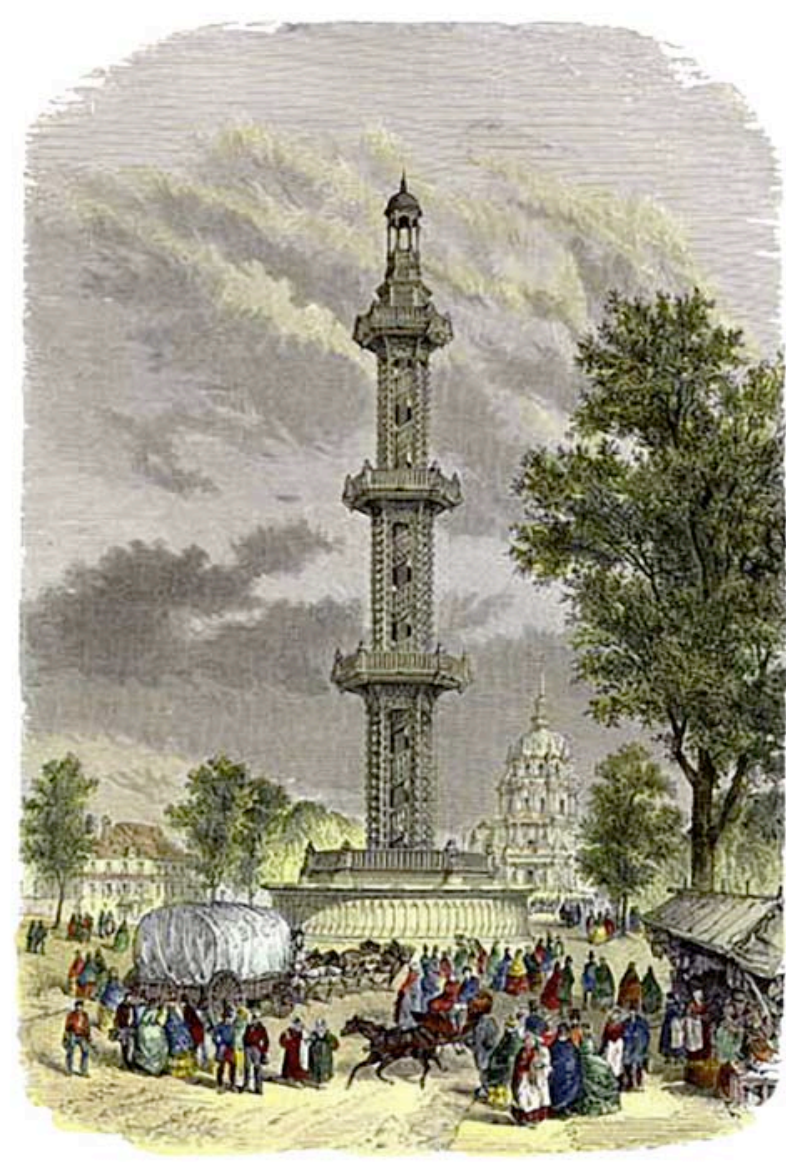

Figure 2. "Artesian Well at Grenelle" wood engraving published in an 1879 encyclopedia (uncopyrighted and freely distributed by http://www.antiqueprints.com). This well, with upgrades made by Dupuit in the early 1850 s, was one of the major municipal supplies of water for the SW side of Paris, along with the Perrier pumping station at Chaillot, which supplied water from the Seine. The external structure as shown here, designed by the architect Delaporte in 1841, was demolished in 1903.

(note: we have replaced Darcy's sum of symbols for the pressure and elevation components of head loss with the single, combined, $\left.h_{L}\right)$. Here $s$ is the total cross-sectional area perpendicular to flow, and $k$ is a coefficient unnamed by Darcy, today called the hydraulic conductivity, which he said depends on the permeability of the sand. As elucidated later, the coefficient also depends on the density and viscosity of the fluid. This is correctly reflected by Slichter's [1899] writing and is evident in connecting equation (6) with Poiseuille's [1841] equation. Darcy [1857] wrote that he and Poiseulle arrived at the same expression under different circumstances, at which point Darcy may have had a fuller understanding of his unnamed coefficient, which Dupuit [1857] referred to as Darcy's "coefficient of the natural layer." Hubbert [1940] would later rigorously define permeability itself, and by also defining the hydraulic potential, would raise the understanding of each term in (6) to a higher level of sophistication.
[27] Dupuit [1857] made a very important step in understanding what happens in the aquifer distal to the well, by using equation (6) to represent flow in the aquifer toward the well, and linking it through conservation of mass with equation (5) to represent head loss at the well. Doing so allowed the determination of Darcy's constant $C$ and gave new insight into aquifer processes. Prior to the derivation, Dupuit discussed that cross sections as in Figure 1 lead one to incorrect thoughts of unidirectional flow, whereas flow will actually radially converge on an artesian well. Thus it is better to conceptualize a circular (in areal view) flow domain of radius $r$ and thickness $B$, and radial flow inward toward the well so that equation (6) is written with $s$ as a cylindrical cross-sectional area perpendicular to flow:

$$
q=k(2 \pi r B) \frac{d h(r)}{d r}
$$

He integrated this expression over an arbitrary distance between $r_{1}$ and $r_{2}$ which gave the following expression [Dupuit, 1857, p. 261]:

$$
h_{L}=h\left(r_{2}\right)-h\left(r_{1}\right)=\frac{q}{2 \pi k B} \ln \left(\frac{r_{2}}{r_{1}}\right)
$$

(note we have replaced Dupuit's symbols with those consistent with Darcy's and the equations above; for example, Dupuit uses $\mu^{\prime}$, which is equal to $[k B]^{-1}$ ). Figure 6 shows Dupuit's plot of this spatial function (in his plot, $H-y$ gives $h_{L}$, today commonly called the drawdown), from the well at radius $r_{1}=r_{w}$ out to the radius of influence at steady state, $r_{2}=L$. Importantly, here Dupuit first showed that the head loss in the aquifer away from the well forms a cone of depression. Many U.S. textbooks incorrectly attribute equation (8) to Thiem [1906].

[28] With this development, Dupuit [1857] determined the constant $C$ in Darcy's equation (5) when there is no well loss. If $h_{0}$ equals the background head at $r=L$, and $h_{1}$ equals the head in the well at $r=r_{w}$, then $q_{0}=0$ and at steady state, with conservation of mass across the well screen, $q_{1}$ equals the $q$ in equation (8), and $\left(h_{0}-h_{1}\right)$ is the drawdown, $h_{L}$, in equation (8). This gives the constant $\mathrm{C}$ in equation (5) as

$$
C=\frac{1}{2 \pi k B} \ln \left(\frac{r_{w}}{L}\right)
$$

Almost a century later, Theis [1935] would show that under transient flow:

$$
C(t)=\frac{1}{4 \pi k B} W(u)
$$

where $W(u)$ is a dimensionless function of time and the diffusivity of the aquifer. Thus $\ln \left(r_{w} / L\right)$ in Dupuit's equation is the large time limit of $W(u) / 2$ when at apparent steady state or when fixed-head boundaries are reached. Thus, the framework for well hydraulics was established by Darcy [1856] and Dupuit [1857], penecontemporaneously with the publication of equations (5) and (8). Equation (5) is still in conventional use today to determine well losses from step- 
Histoire des Fontaincs publiques de Dijon.

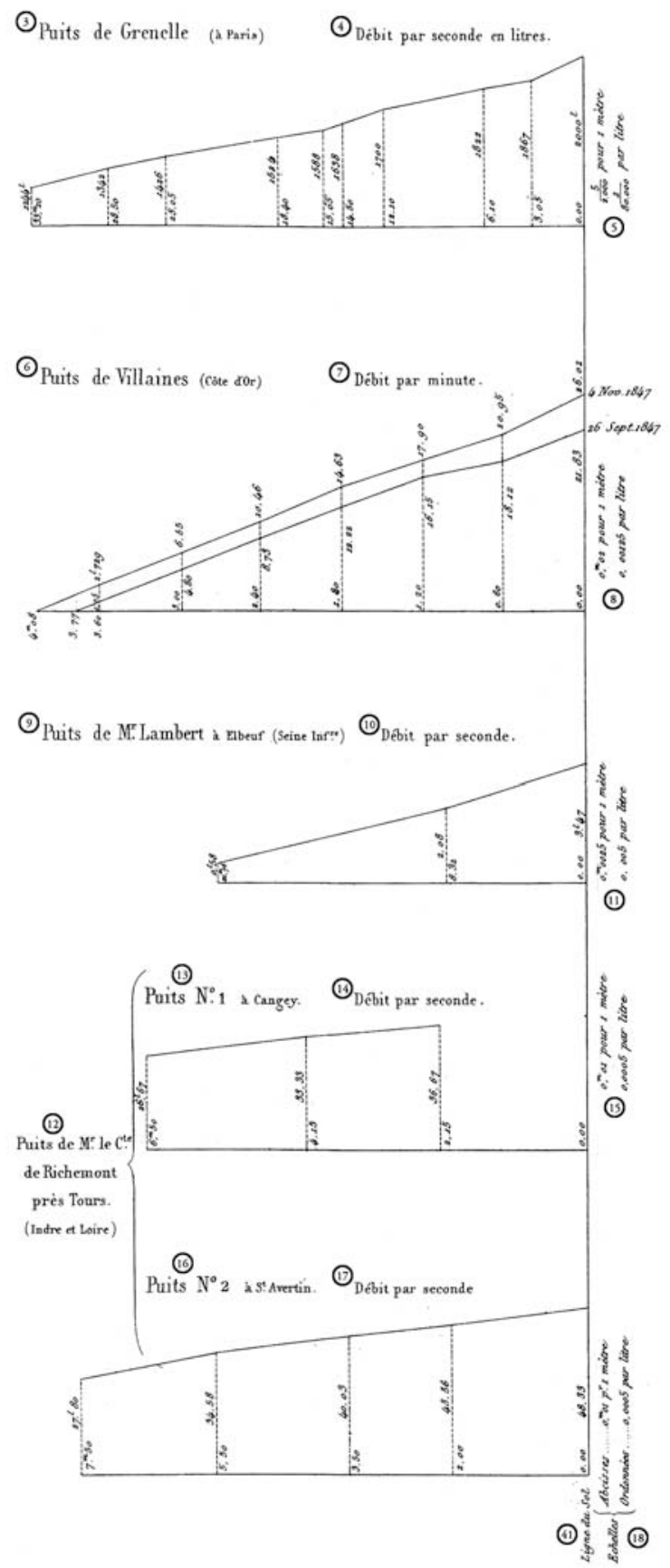

(1) Planche 22.

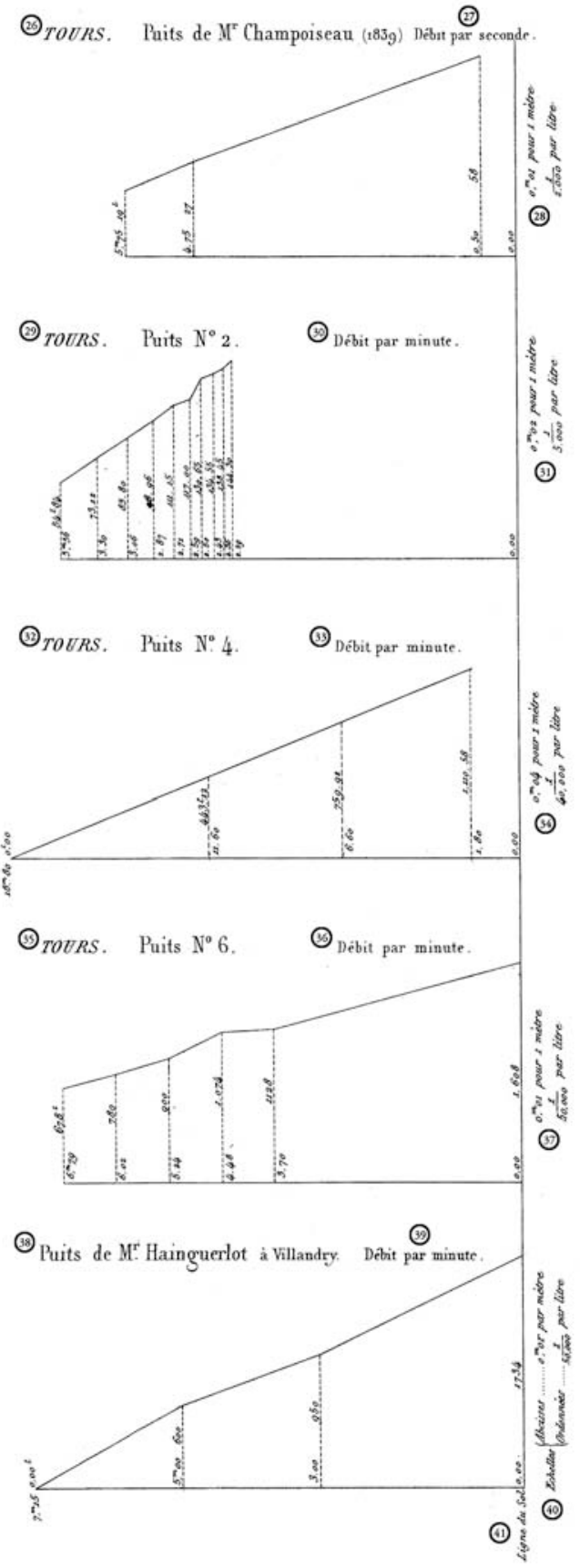

Gravi par Dulas.

Figure 3. Plots of data collected from systematically changing the height of discharge for artesian wells [from Darcy, 1856] (see Figure 4a). Each plot represents a different artesian well. The abscissa is elevation of the discharge orifice, decreasing to the right, and the ordinate is the discharge rate (increasing upward; see Figure 4b). Each vertical line represents a datum from an experiment.

drawdown pumping tests [cf. Driscoll, 1986, p. 556, equation (16.8)].

[29] Dupuit [1857, p. 261] noted that equation (8) reveals that the shape of spatial head loss between $r_{w}$ and $L$ is conical independent of the $k$ or $B$ of the layer, but the magnitude of $q$ per unit head loss out in the aquifer is linearly proportional to $k$ and/or $B$. Furthermore, Dupuit [1857, p. 267] pointed out that while cones of depression must exist around the wells at Grenelle and Tours which Darcy [1856] had discussed, the $k B$ is larger at Tours than at Grenelle, and if Grenelle had the same $k B$ then discharge per head loss would increase by fifteenfold. 
a.

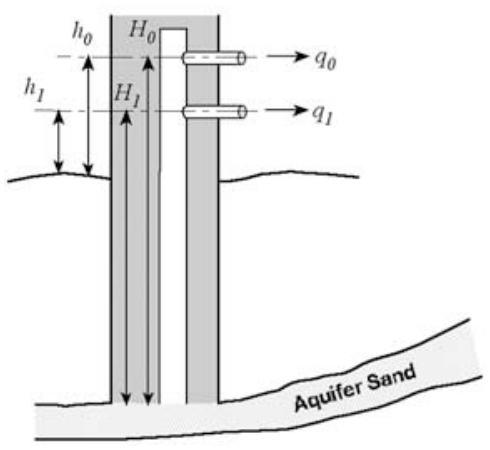

b.

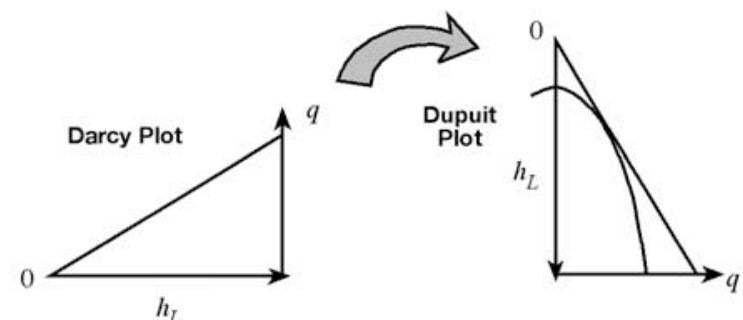

Figure 4. (a) Enlargement of the left well in Figure 1 but with the symbols of Darcy's [1856] equation (our equation (5)) added. (b) The relation between the plot of Darcy [1856] in Figure 3 and the plot of Dupuit [1857] in Figure 5.

[30] Both Darcy [1856, p. 88] and Dupuit [1857, p. 262] showed that because the second part of the LHS of equation (5) is negligible among the artesian wells considered, increasing the radius of the well will have a negligible effect on flow rates. In support of this, Darcy computed the large-radius limit for the Grenelle well showing it would give negligible additional flow compared to the current diameters of the riser pipe sections. Dupuit followed

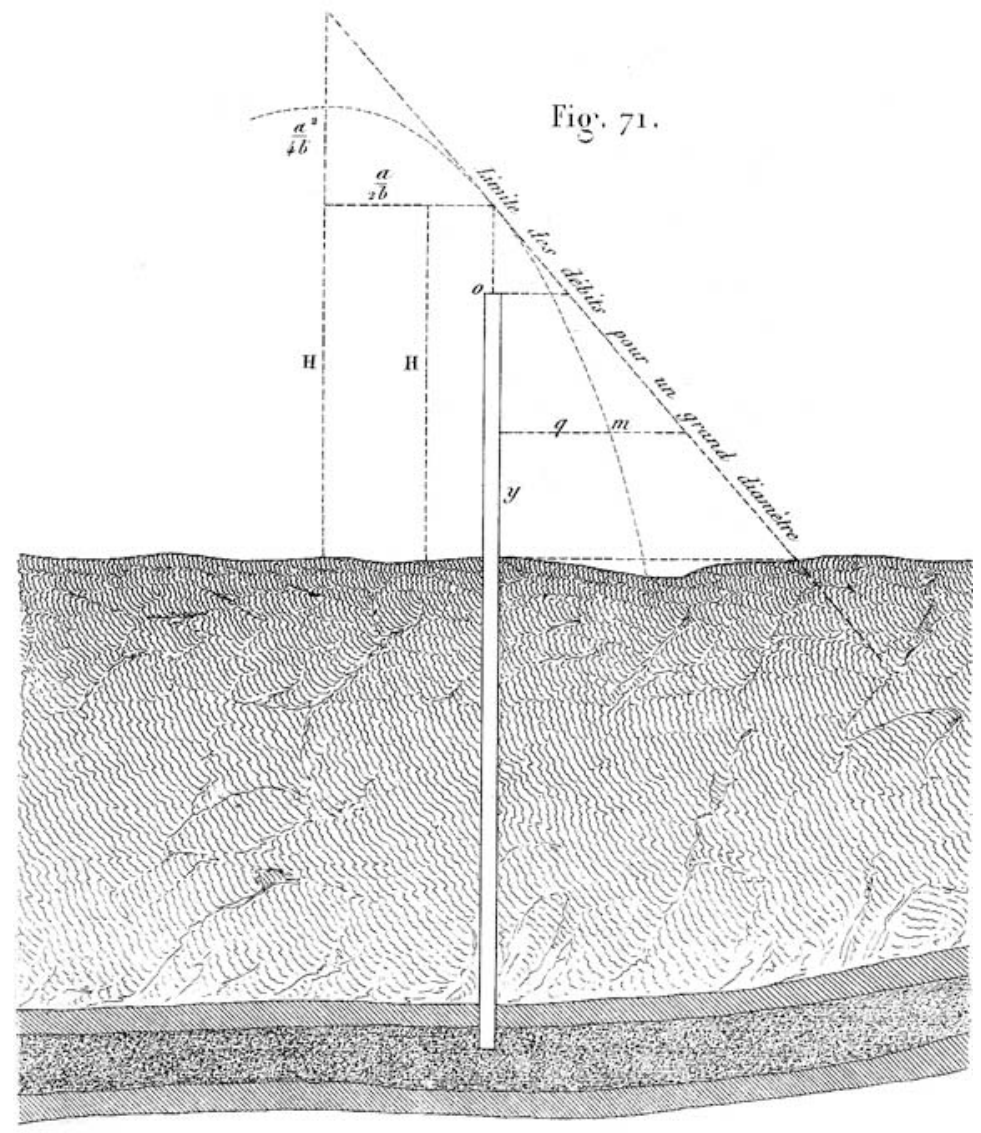

Figure 5. Difference between linear and parabolic behavior in the artesian well experiments [from Dupuit, 1857]. The relationship to the plots in Figure 3 is given in Figure 4b. Dupuit's symbols are not consistent with Darcy's. If head loss occurred primarily because of high-velocity flow up the riser pipe, the second term on the left-hand side (LHS) of equation (5) would dominate, giving the parabolic curve. If head loss occurred primarily because of low-velocity seepage through the aquifer sand, the first term on the LHS of equation (5) would dominate, giving the straight line behavior and maximum-limit discharge ("limite des débits"). The data in Figure 3 all show the straight line behavior. 
Fig. $6_{9}$.

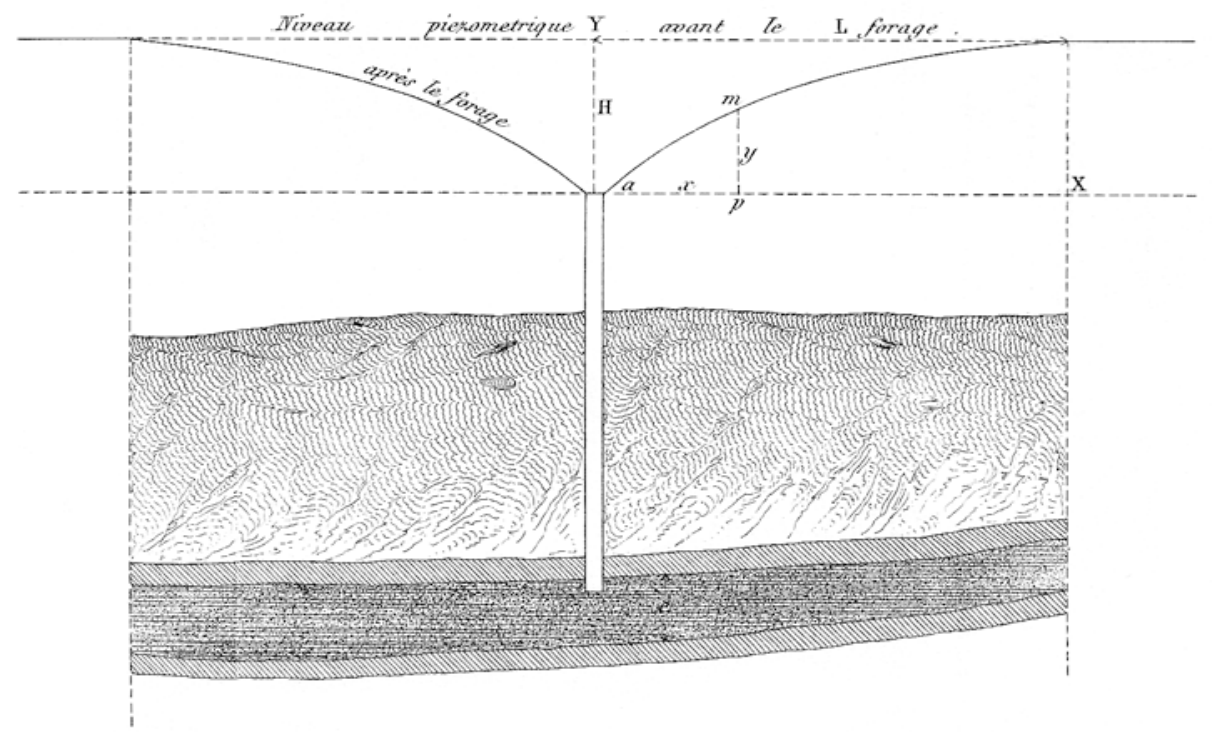

Figure 6. Plot from Dupuit [1857] showing that the radial seepage through sands, toward the well, causes head loss with a cone of depression in the piezometric level ("niveau piézométrique").

by discussing how the area of the intake was reduced while repairing an accident, with no affect on the flow rate. Dupuit [1857, p. 261] stated:

\footnotetext{
The proportionality of the volume rate of flow to head difference (as per the constant $\mathrm{C}$ ) has been demonstrated by numerous experiments done on various artesian wells, including the Grenelle well, among others. This is discussed in Mr. Darcy's work, which we have cited. Thus, there is a rather remarkable confirmation of the formulas we have derived
}

[31] After presenting how to quantify aquifer head loss around an artesian well, Dupuit [1857, p. 265] stated that a new well was to be drilled at Passy, about $3 \mathrm{~km}$ from the
Grenelle well, in the same formation. He stated that questions on the diameter of the well were not important, in light of the previous development. He stated that if it were drilled into the same formation, with same thickness, permeability and initial head, it should provide essentially the same yield regardless of having a similar diameter versus a much larger diameter. He argued that the more important question was whether or not a flowing well at Passy will lower the yield at Grenelle. This led to an important presentation of ideas about well interference and capture zone geometries. Here, Dupuit was following up on Darcy's [1856, p. 105] discussion of the "reciprocating" effect of multiple artesian wells at Tours (Figure 3). If one well were shut off, yields at

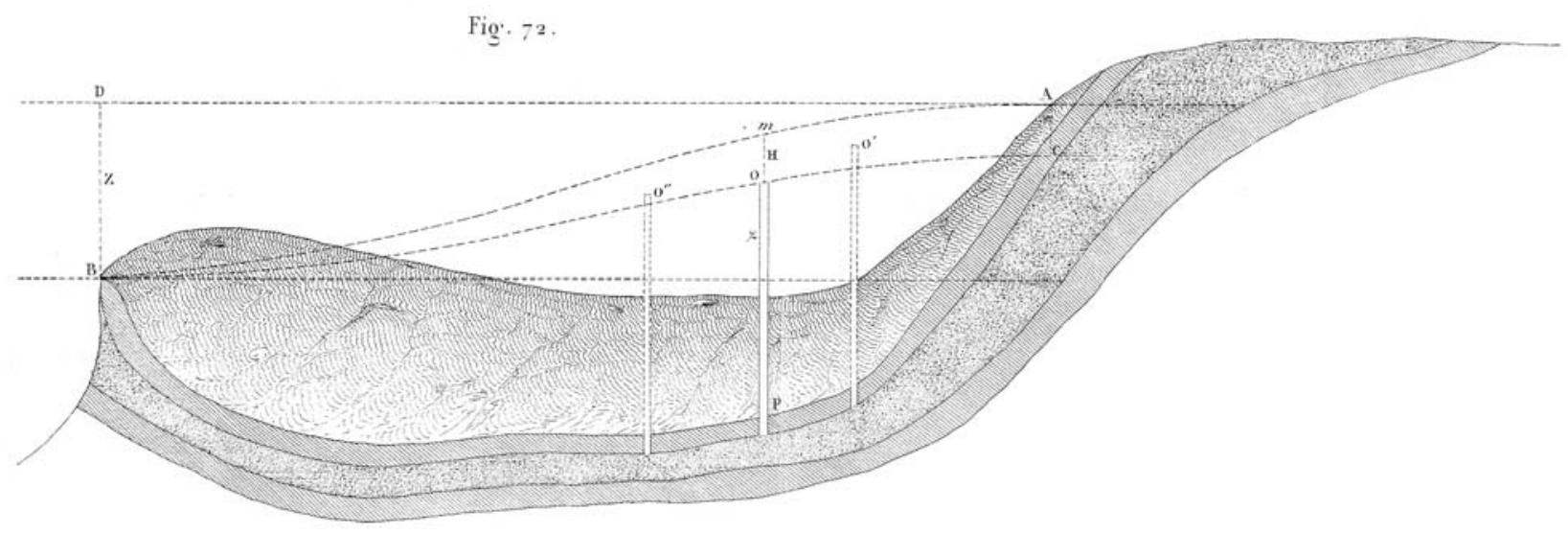

Figure 7. An aquifer stratum that is recharged on the right, at the edge of the Paris basin, and which is exposed downgradient in the wall of one of the major river valleys (e.g., the Seine), creating spring discharge [from Dupuit, 1857]. This scenario is discussed by Darcy [1856, note 56]. Note that the regional piezometric gradient steepens over the interval where the stratum is thinner, illustrating steady state relationships Dupuit explored using Darcy's law. The figure is used as the starting point for Dupuit's analysis of reciprocal effects (superposed drawdown) among proximal wells tapping the same stratum. 

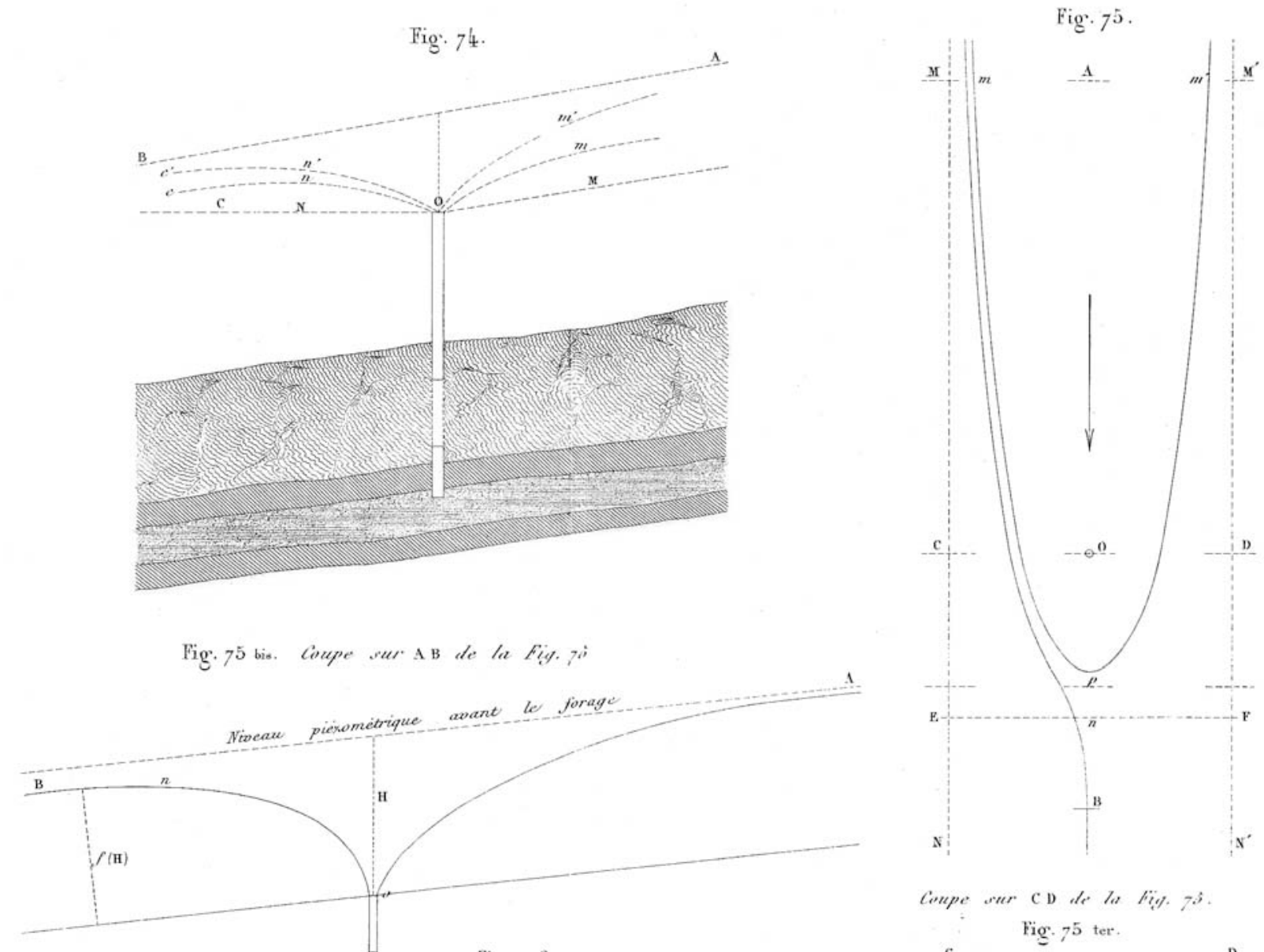

Fig. $7^{6}$.
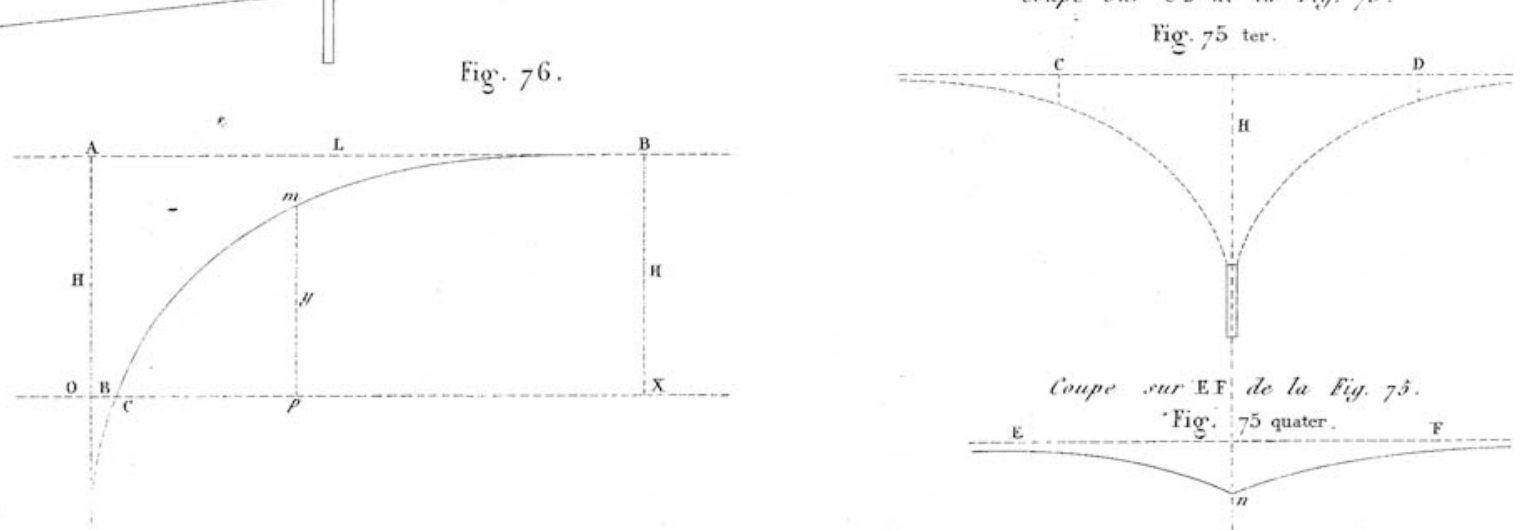

Figure 8. Capture zone geometry for a well discharging from an aquifer with a regional gradient [from Dupuit, 1857].

nearby wells increased. Dupuit noted that the wells at Tours were closer than the distance between Passy and Grenelle, but that interference was a possibility.

[32] Dupuit [1857, p. 267] then gave an interesting analysis of the superposition of the drawdowns created by multiple, flowing wells. He began the analysis by considering multiple, fully penetrating wells in an aquifer cross section with no width into the plane of the section as in Figure 7, (or equivalently, as he stated, with the case of wells that are like drains extending infinitely into the plane). Here the consideration of superposition is fairly trivial, because the head in each upgradient well is a boundary condition for flow to the downgradient well. Importantly, Dupuit [1857] (p. 270, section titled "Reciprocating influence of artesian wells in the same layer") stated that the natural system is not like that, but rather one must consider a multitude of sections extending radially from each well. As shown in Figure 8, Dupuit [1857, Figure 75] made the important logical step of superposing the cone of depression created by any one well onto the regional flow field, showing that the zone of influence (conventionally called a capture zone geometry today) will be asymmetric around a well. Here Dupuit states that inside 


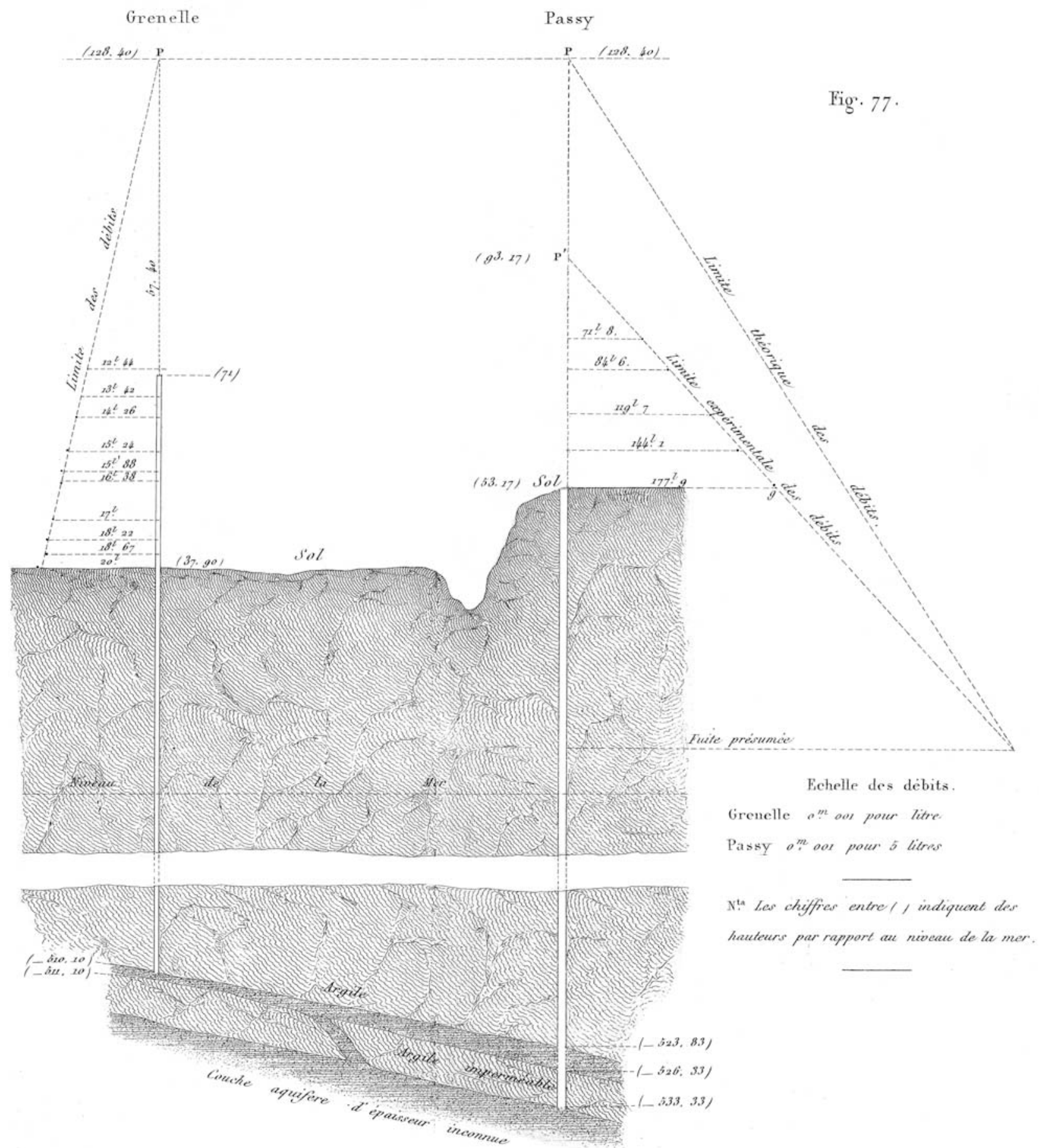

Figure 9. Heterogeneity in the sand formations tapped by the artesian wells at Grenelle and Passy [from Dupuit, 1857]. Note that the thicker formation tapped by the Passy well gives a smaller slope (less head loss per unit discharge) in the orifice elevation versus discharge plot.

of the zone of influence, head is affected. However, water flowing outside the zone is not captured. This principle is of course fundamentally important today in the design of pumpto-treat groundwater remediation systems or gradient control wells. Focusing on the prospects of a Passy well, Dupuit stated that in knowing head at only one well at Grenelle, and thus not knowing the regional head, the potential for effects at Passy cannot be calculated.
[33] During the time that Dupuit [1857] was in review by the French Academy, the well at Passy was drilled, and completed with a larger well diameter. The yield at Passy was of the order of 30 times greater than at Grenelle, and thus the Academy's review was critical of Dupuit (and Darcy's) contention that yield at Grenelle was essentially controlled by head loss in the aquifer, not by the diameter of the riser pipe. Dupuit appended a new section to the original 1857 monograph [Dupuit, 1863, section 152, p. 277ff.] that 
Fig. 63.

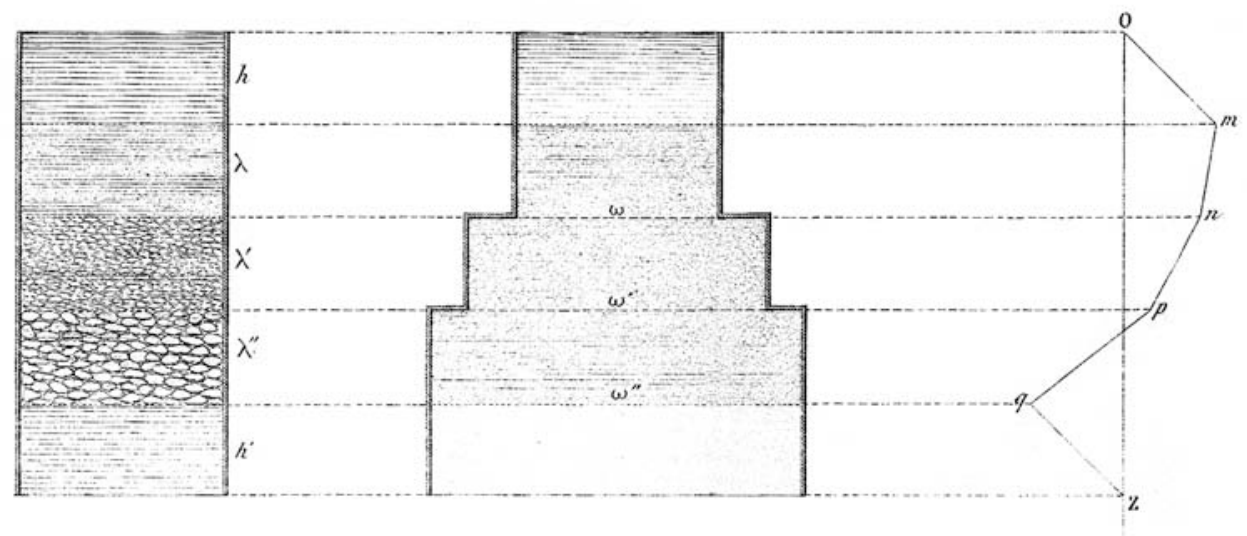

Figure 10. (right) Vertical profile of pressure head (increasing to the right) for (middle and left) either of the two containers [from Dupuit, 1857]. The leftmost container has uniform width, and intervals $\left[\lambda, \lambda^{\prime}\right.$, $\left.\lambda^{\prime \prime}\right]$ have increasingly coarser (higher $k$ ) sediment. There is pure water above and below these intervals. The middle container has uniform $k$ sediment but different widths $\left[\omega, \omega^{\prime}, \omega^{\prime \prime}\right]$.

summarized the critique and responded to it. Figure 9 shows Dupuit's [1863] application of the principle in equations (5) and (9) to explain the differences between the well yields. Figure 9 shows that the aquifer is not "layer cake" uniform, and the Passy well intersects a thicker section of sandstone. Thus the plotted profiles of $q$ versus $h_{L}$ for each well are both linear, but $\mathrm{C}$ is smaller (more $q$ per unit $h_{L}$ ) for the Passy well because $B$ is larger (and perhaps $k$ also is larger). Dupuit pointed out that the principles of mechanics that Darcy and he applied to permeable terrains provide a logical explanation for the differences. He also pointed out that the yield at Grenelle was impacted when the Passy well was brought into production.

\section{Further Quantification of Flow Through Sediments Including Residence Times, Effective Conductivities, and Free-Surface Boundaries}

[34] Darcy [1856] began with a discussion of identifying public water supplies, including a review of what he knew about artesian wells. Dupuit [1857] was organized differently, more as a text on applying the principles of fluid mechanics to understanding flow through permeable terrains.

[35] Dupuit's [1857] introductory discussion of fluid mechanics reviewed Darcy's linear law for low-velocity flow. In extending the result to flow through sand, Dupuit [p. 233] reviewed Darcy's sand column experiments and discussed the grain size distribution of the sediment that Darcy used, noting that the porosity, $\varphi$, was 0.38 . He pointed out that Darcy's $\frac{q}{s}$ was the rate over the total cross-sectional area. Dupuit pointed out that the average linear velocity of the fluid is the rate per cross-sectional area of pores and thus is given by dividing the Darcy flow rate by $\varphi$. Dupuit [1857, p. 233] discussed the fact that there are numerous "sinuosités" or tortuous pathways of fluid at the pore scale, and that the real speed is always a little more than what we project onto the (linear) axis of their general direction. Dupuit [1857, p. 249] later pointed out that the average linear velocity could be used to determine the time for groundwater to traverse a permeable terrain over distance $l$ :

$$
t=\frac{\varphi s}{q} l
$$

Dupuit [1857, p. 248] then considered the implication of Darcy's law for nonuniform head loss given that the permeability or thickness of the permeable layer may vary. He considered various containers ("vases") of sediments as analogs. One example in Figure 10 shows his drawing of two containers of sediment to illustrate these effects. The left container has a uniform area perpendicular to flow, and layers that systematically change to coarser-grained (higher $k$ ) sediment downward across each contact. The right container has homogeneous sediment, but the area perpendicular to flow systematically increases downward at each change in width. He considered conservation of mass at steady state, so that in the left illustration the volume rate across the boundary of each sediment layer does not change, and on the right, the volume rate across the transition to wider widths does not change. The plot to the far right shows the pressure head as a function of elevation. Note that the free water at the top and bottom of the illustrations is shown to be at atmospheric pressure. Two important points were made. One point was that through equation (6), we see that increasing $k$ has the same effect as increasing the area perpendicular to flow Dupuit [1857, p. 249]. The other point is that the effective $k$ for flow across layers, $\bar{k}$, is the harmonic mean. Dupuit [1857, p. 248] derived for the left illustration in Figure 10:

$$
\bar{k}=\frac{\left(\lambda+\lambda^{\prime}+\lambda^{\prime \prime}\right)}{\frac{\lambda}{k}+\frac{\lambda^{\prime}}{k^{\prime}}+\frac{\lambda^{\prime \prime}}{k^{\prime \prime}}}
$$

where $\lambda, \lambda^{\prime}, \lambda^{\prime \prime}$ are the layer thicknesses, as noted. The pressure head profile and a careful reading of Darcy's Appendix D, show that both Dupuit and Darcy understood 
that the law of linear head loss applied over negative or positive gauge pressures. If we are to critique Figure 10, it is clear from equation (6) that the gradient should be greatest across $\lambda$ and least across $\lambda^{\prime \prime}$, opposite from what is shown. It seems that Dupuit would have been clear on this, and others have pointed out numerous drafting errors in the plates of Darcy [1856], so perhaps this was also a drafting error.

[36] For 1-D flow or such "container" flow, Darcy [1856, Appendix D, p. 459, equation (1)] also applied conservation of mass to consider transient changes in water level, a distance $\xi$ above to top of a uniform sand column of height $l$, so that

$$
\frac{q(t)}{s}=k \frac{(\xi+l)}{l}=\frac{-d \xi}{d t}
$$

which, after separation of variables, and integration from $h_{o}$ to $h$ over interval $t_{o}$ to $t$ gives:

$$
\ln (h(t)+l)=\ln \left(h_{0}+l\right)-\frac{k}{l}\left(t-t_{0}\right)
$$

Today we call this the falling-head permeameter equation. Darcy had Ritter perform the falling-head test with their (now well known) permeameter apparatus containing sand, and with only water. The linear law was verified for the sand filled tests, and the equivalent transient equation based on the parabolic law, which Darcy also gave, was also verified with tests using only water.

[37] In discussing quantification of hydrogeologic attributes, Darcy [1856, p. 121, notes 44 and 45] shows great familiarity with the wide range of flow conditions one encounters in nature, including (1) groundwater filtration through clastic sediments and sedimentary rocks, (2) filtration through fractures or solution networks, that behave in aggregate as do sedimentary formations, and (3) highvelocity, stream-like flows in large karst conduits. Accordingly, he discussed using the linear and parabolic forms of equation (14) for transient changes, in this context, to evaluate whether springs are supplied by sand-like porous flow versus pipe-like cavity flow, while invoking questions about the famous spring at Nimes. Thus, Darcy extended quantitative hydrogeology beyond steady state considerations. Darcy was aware of phenomena that were difficult to explain including intermittent and cyclical spring discharge, largely out of phase with rainfall events. He discussed the application of the basic principles of groundwater mechanics to explain these phenomena.

[38] All of Dupuit's ideas are applied to both water table ("surface libre") and confined ("surface forcée") aquifers. Sadly, Dupuit is perhaps known to many practicing U.S. hydrogeologists only for how he treated the existence of a free-surface upper boundary (the water table) in unconfined groundwater flow. He considered horizontal 1-D or 2-D radial flow and let $s=h w$ where $w$ is width perpendicular to flow. For 1-D flow, substituting into (4) and integrating for a head drop between $h_{o}$ and $h$, over a distance from 0 to $L$, Dupuit [1857, p. 236] wrote

$$
q=\frac{k w}{2} \frac{\left(h_{0}^{2}-h^{2}\right)}{L}
$$

Dupuit [1857, p. 255] presented the corresponding form of equation (8) from the same approach. The approach is conventional today when the vertical components of velocity can be ignored. The slight of only recognizing this one contribution in U.S. textbooks is made worse by the fact that the idea is referred to as the Dupuit-Forchiemer approach, though Forchiemer's work did not appear until 30 years later.

\section{Discussion}

[39] Darcy [1856] is an amalgamation of sections of prose, each with distinctly different character. Some sections are very much like a handbook on methods of water supply. Some sections present Darcy's untested ideas (a new river filter) or novel approaches that recently came into Darcy's awareness (wind-driven water pumps). Some sections review Darcy's knowledge of the philosophy of natural history as it relates to springs and the hydrologic cycle, including quotes from Greek scholars. Some sections are developed like a research paper, presenting derivations of equations and discussing new findings. Some sections are like essays, such as in describing water quality, public health, and the need for free water distribution. Darcy's vernacular style is consistent with someone who, with failing health, is trying to get all of his important thoughts recorded to paper.

[40] In contrast, Dupuit [1857] is organized more like a scientific text. The organization is clearly described within the introduction: First the relevant principles of fluid mechanics are covered and, as per Darcy, applied to porous media. Then various configurations of sand-filled containers are considered, as aquifer analogs. Finally, these principles are applied to understanding flow in confined and in unconfined aquifers.

[41] Despite the disparate styles, both Darcy [1856] and Dupuit [1857] are clear and consistent on the use of the law of how head loss changes from linear to parabolic depending on the magnitude of the velocity. They both use it to differentiate aquifer head loss from head loss in well riser pipe. They have the same conceptual model for hydrogeology, spring flow, and artesian wells in the Paris basin. They both have considerable focus on the artesian well at Grenelle and on reciprocal effects of wells when more than one produces from the same layer. In general, both focus on applying fluid mechanics to quantitatively describe subsurface fluid flow. Freeze and Back [1983] described Darcy and Dupuit's focus as at the scale of a laboratory column or well. However, our review of Darcy and Dupuit's complete contributions illustrates that they understood hydrogeology at a regional scale, and they developed a quantification of processes at the scale of a geologic stratum tapped by one or more wells. The discussion of regional hydrogeology at the scale of systems of multiple strata and aquifers (e.g., all of the strata in Figures 1 or 7) would remain mostly qualitative up until the quantitative studies of equipotential lines and flow lines at that scale by Tóth [1963] and Freeze and Witherspoon [1967].

[42] Darcy's sand column experiments were not completed by Darcy and Ritter until February of 1856. "Les Fontaines" was completed in August 1856 (6 months later). The linear law for head loss in flow through sands examined in Appendix D is used throughout "Les Fontaines," including 
Table 1. Timeline of the Education and the Career Contributions of Darcy and Dupuit and Related Events

\begin{tabular}{|c|c|}
\hline Year & Event \\
\hline 1803 & Darcy is born on 10 June \\
\hline 1804 & Dupuit is born on 18 May \\
\hline 1821 & Darcy enters L'Ecole Polytechnique \\
\hline 1822 & Dupuit enters L'Ecole Polytechnique \\
\hline $1823-1824$ & Darcy and Dupuit enter L'Ecole des Ponts et Chaussées \\
\hline 1826 & Darcy graduates, enters Corps des Ponts et Chaussées and is assigned to Jura \\
\hline 1827 & $\begin{array}{l}\text { Darcy assigned to Dijon } \\
\text { Dupuit graduates enters Corns de Ponts et Chaussées and is assioned to Sarthe }\end{array}$ \\
\hline 1829 & Drilling of artesian well at Place Saint-Michel started in Dijon in March \\
\hline $1832-1833$ & Darcy gauges the Rosoir spring \\
\hline $1833-1834$ & Dupuit conducts experiments on wheels and road friction \\
\hline & $\begin{array}{l}\text { Darcy issues report with Dijon water supply plan that contains data showing aquifer } \\
\text { head loss with flow to artesian wells }\end{array}$ \\
\hline 1837 & Darcy severely injured in a railcar accident \\
\hline 1839 & Rosoir to Dijon aqueduct construction started on 21 March \\
\hline 1840 & $\begin{array}{l}\text { First arrival of water in Dijon on } 6 \text { September } \\
\text { Dupuit transferred to Marne }\end{array}$ \\
\hline 1842 & Darcy receives Legion of Honor \\
\hline 1843 & $\begin{array}{l}\text { Darcy receives gold medal from Dijon municipal council } \\
\text { Dupuit receives Legion of Honor for research on roads and pavements }\end{array}$ \\
\hline 1844 & $\begin{array}{l}\text { Experiments of head loss versus riser pipe height at Grenelle conducted } \\
\text { Dupuit, as Chief Engineer of Maine-et-Loire, publishes "De la Mesure de 1'Utilité } \\
\text { des Travaux Publics," starting the foundation of microeconomics }\end{array}$ \\
\hline 1845 & Darcy's plan for bringing the Paris to Lyon rail through Dijon accepted \\
\hline 1846 & Dupuit witnesses floods of River Loire \\
\hline 1847 & $\begin{array}{l}\text { Darcy channelizes the Suzon through Dijon } \\
\text { Experiments of head loss versus riser pipe height at Tours conducted }\end{array}$ \\
\hline 1848 & $\begin{array}{l}\text { February Revolution; Darcy removed from Dijon } \\
\text { After temporary appointment to Bourges, Louis Napoleon takes office, and Darcy is } \\
\text { transferred to Paris and is appointed Chief Director for Water and Pavements }\end{array}$ \\
\hline 1849 & $\begin{array}{l}\text { Darcy's pipe flow experiments started at Chaillot on } 31 \text { August } \\
\text { John Snow and William Bud publish articles linking cholera to public water supplies }\end{array}$ \\
\hline 1850 & $\begin{array}{l}\text { Darcy promoted to inspector general, 2nd class, in Paris } \\
\text { Dupuit called to Paris in May and groomed to succeed Darcy as Chief Director for } \\
\text { Water and Pavements }\end{array}$ \\
\hline 1851 & Darcy's experiments at Chaillot completed on 27 October \\
\hline 1852 & $\begin{array}{l}\text { Council on Public Health held in Brussels connects public health with water supply } \\
\text { (discussed by Darcy [1856]) }\end{array}$ \\
\hline 1853 & As a sign of failing health, Darcy passes out in the street \\
\hline 1854 & $\begin{array}{l}\text { Darcy completes report on pipe flow experiments at Chaillot; report goes into 3-year review } \\
\text { Dupuit publishes book on theory of pipe flow, Paris supply wells, and sewer improvements } \\
\text { John Snow removes pump handle from Broad St. well }\end{array}$ \\
\hline 1855 & $\begin{array}{l}\text { Darcy released of duties except for research } \\
\text { Darcy starts permeameter experiments at the Dijon Hospital }\end{array}$ \\
\hline 1856 & Darcy publishes "Les Fontaines Publiques de la Ville de Dijon" \\
\hline 1857 & $\begin{array}{l}\text { Dupuit completes "Mouvement de l'Eau à Travers les Terrains Perméables," which } \\
\text { goes into review by the Academy of Sciences }\end{array}$ \\
\hline 1858 & Darcy's death on 3 January \\
\hline 1861 & Experiments of head loss versus riser pipe height at Passy conducted \\
\hline 1863 & $\begin{array}{l}\text { Dupuit publishes "Mouvement de l'Eau à Travers les Terrains Perméables" } \\
\text { as chapter } 8 \text { in larger book on hydraulics }\end{array}$ \\
\hline 1864 & Pasteur lectures on the germ theory of disease \\
\hline 1866 & Dupuit's death on 5 September \\
\hline
\end{tabular}

analyses of data on artesian wells and springs collected a decade earlier. The many questions about linear versus parabolic flow in aquifers and springs would probably not have come up, been answered, and written into so many different parts of the text within such a short 6-month interval. Rather, many of the ideas had probably begun to crystallize in Darcy's thinking for years prior to 1856. Indeed, as discussed by Brown [2002], Darcy's interest in quantifying groundwater processes was sparked at the beginning of his career, and he would have ruminated over questions about head loss in aquifers for decades (Table 1). The basic law of linear versus parabolic head loss discovered at Chaillot provided a foundation with which to address many of these questions. Between 1851 and 1857, Darcy would have had 6 years to apply this law to his thinking about the linear data from artesian wells (Figure 3), and his wealth of early experience with spring flows. In a similar vein, Dupuit [1857] was submitted 1 year after the sand column experiments. It is not likely that all his ideas, derivations, and writing, and figure production would have occurred in just 1 year. More likely, Dupuit and Darcy, while together in Paris in the highest circles of the Inspector General's office and Ponts et Chaussées Council, thought about and discussed the ramifications of their collective pipe flow experiments at the Chaillot facility, and the linear law of low-velocity flows which came out of those experiments, starting in 1851, well before the sand column experiments. Furthermore, Dupuit was in charge, 
under Haussmann, of the expansion of water supply and sewer service in Paris. This included upgrades of the artesian well at Grenelle [Mahyer, 1866]. It seems very likely that Darcy and Dupuit would have carefully considered and discussed the linear data from the riser pipe experiments conducted some 10 years earlier at Grenelle (in 1844, as plotted in Figure 3), and would have started to realize the significance of the 1849-1851 pipe flow experiments in explaining those 1844 results. Indeed, as stated by Brown [2002], the sand column experiments probably confirmed a hypothesis they would have held with great confidence.

[43] In closing, clearly Darcy's linear law of fluid mechanics is widely applied to quantifying various aspects of groundwater flow by both Darcy [1856] and Dupuit [1857]. The range of groundwater processes or attributes which are quantified and elucidated include: groundwater flow rate as a linear function of driving force, average linear velocity, average travel time, effective hydraulic conductivity for layered heterogeneity, conservation of mass in confined and unconfined flow, the nature of the regional piezometric surface, porous flow versus flow through discrete fractures and karst conduits, the concept and equation for a cone of depression around flowing wells, superposition of the effects of multiple wells, and capture zone geometries of wells within a regional flow field. This review of the comprehensive contributions to quantitative hydrogeology by Darcy [1856] and Dupuit [1857] shows that many, if not a majority, of the principles of steady state quantitative hydrogeology which are commonly introduced in the beginning chapters of hydrogeology textbooks were established with the nearly simultaneous publication of these documents.

[44] Acknowledgments. The first author was introduced to the history of hydrogeology by Stanley Davis and found continual enthusiasm and encouragement for its study through William Back. Catherine Masteau at the Ecole Nationale des Ponts et Chaussées, la Section Historique, and Diana Kaylor in the Paul Lawrence Dunbar Library at Wright State University facilitated access to historical documents. The manuscript was improved from helpful suggestions in reviews by Glenn Brown, Ghislain de Marsily, and T. N. Narasimhan.

\section{References}

Bobeck, P. (2004), The Public Fountains of the City of Dijon, Henry Darcy, 1856, translated from French, Geotech. Transl., Austin, Tex.

Brown, G. O. (2002), Henry Darcy and the making of a law, Water Resour. Res., 38(7), 1106, doi:10.1029/2001WR000727.

Brown, G. O. (2003), Henry Darcy's perfection of the pitot tube, in Henry P. G. Darcy and Other Pioneers in Hydraulics, edited by G. O. Brown, J. D. Garbrecht, and W. H. Hager, pp. 14-23, Am. Soc. of Civ. Eng., Reston, Va.

Brown, G. O. (2004), Jules Dupuit's contributions in water resources, in Water Resources and Environmental History, edited by J. R. Rogers, G. O. Brown, and J. D. Garbrecht, pp. 104-110, Am. Soc. of Civ. Eng., Reston, Va.

Caudemberg, G. (1858), Notice sur M. Henri Darcy, in Mémoires de l' Académie de Dijon, Loireau-Feuchot, Dijon, France.

Darcy, H. (1834), Rappport à le maire et au conseil municipal de Dijon, sur les moyens de fournir l'eau nécessaire à cette bille, Douillier, Dijon, France.

Darcy, H. (1856), Les Fontaines Publiques de la ville de Dijon, Dalmont, Paris.

Darcy, H. (1857), Recherches Experimentales Relatives au Mouvement de l'Eau dans les Tuyaux, Mallet-Bachelier, Paris.
Darcy, H. (1858), Recherches experimentales relatives au mouvement de l'eau dans les tuyaux, in Mémoires Présentés par Divers Savants à l'Académie des Sciences de l'Institut Impérial de France, Paris, vol. 15, 14-401, Acad. Des Sci. de l'Inst. Imp. de France, Paris.

Driscoll, F. G. (1986), Groundwater and Wells, 1089 pp., Johnson Div., St. Paul, Minn.

Dupuit, J. (1854), Traite Theorique et Pratique de la Conduite et de la Distribution des Eaux, Carilian-Goeury et Dalmont, Paris.

Dupuit, J. (1857), Mouvement de l'eau a travers le terrains permeables, C. R. Hebd. Seances Acad. Sci., 45, 92-96.

Dupuit, J. (1863), Etudes Theoriques et Pratiques sur le Mouvement des Eaux dans les Canaux Decouverts et a Travers les Terrains Permeables, 2nd ed., Dunod, Paris.

Freeze, R. A. (1994), Henry Darcy and the fountains of Dijon, Ground Water, 32(1), 23-30, doi:10.1111/j.1745-6584.1994.tb00606.x.

Freeze, R. A., and W. Back (Eds.) (1983), Physical Hydrogeology, Benchmark Pap. Geol., vol. 72, Hutchinson Ross, Stroudsburg, Pa.

Freeze, R. A., and P. A. Witherspoon (1967), Theoretical analysis of regional groundwater flow: 2 . Effect of water-table configurations and subsurface permeability variation, Water Resour. Res., 3(2), 623-634, doi:10.1029/ WR003i002p00623.

Gisonni, C. (2003), Henry Darcy and the pipe flow formula, in Henry P.G. Darcy and Other Pioneers in Hydraulics, edited by G. O. Brown, J. D. Garbrecht, and W. H. Hager, pp. 24-37, Am. Soc. of Civ. Eng., Reston, Va.

Hager, W. H. (2003), Henry Darcy-Biography by Caudemberg, in Henry P.G. Darcy and Other Pioneers in Hydraulics, edited by G. O. Brown, J. D. Garbrecht, and W. H. Hager, pp. 51-70, Am. Soc. of Civ. Eng., Reston, Va.

Hager, W. H. (2004), Jules Dupuit—Eminent hydraulic engineer, J. Hydraul. Eng., 130(9), 843-848, doi:10.1061/(ASCE)0733-9429(2004)130:9(843).

Hubbert, M. K. (1940), The theory of groundwater motion, J. Geol., 46, $785-944$.

Lochot, E. (2003), L'homme et ses réalizations, in Henry Darcy, Le Bicentenaire 1803-2003, pp. 7-21, Temps Reel, Dijon, France.

Lyell, C. (1834), Principles of Geology, vol. 4, 3rd ed., John Murray, London.

Mahyer, M. (1866), Notice necrologique sur M. Dupuit, inspecteur general des ponts et chausses, Ann. Ponts Chaussees, 36(2), 177-183.

Meinzer, O. E. (1923), The occurrence of groundwater in the United States, with a discussion of principles, U.S. Geol. Surv. Water Supply Pap., 489.

Phillip, J. R. 1995, Desperately seeking Darcy in Dijon, Soil Sci. Soc. Am. $J ., 59,319-324$.

Poiseuille, J. L. (1841), Recherches expérimentales sur le mouvement des liquids dans les tubes de très-petits diamèters, Acad. des Sci., Paris.

Rat, P. (2003), Les eaux de Dijon, in Henry Darcy, Le Bicentenaire 18032003, pp. 53-71, Temps Reel, Dijon, France.

Reynolds, O. (1883), An experimental investigation of the circumstances which determine whether the motion of water shall be direct or sinuous and of the law of resistance in parallel channel, Philos. Trans. R. Soc. London, 174, 935-982, doi:10.1098/rstl.1883.0029.

Rouse, H., and S. Ince (1957), History of Hydraulics, Iowa Inst. of Hydraul. Res., Univ of Iowa, Iowa City, Iowa.

Simmons, C. (2007), Henry Darcy (1803-1858), Immortalized by his scientific legacy, in Aquifer Systems Management, Darcy's Legacy in A World of Impending Water Shortage: Proceedings of the International Association of Hydrogeologist, Darcy Symposium, Dijon, June 2006, edited by L. Chery and G. de Marsily, pp. 3-24, Taylor and Francis, Leiden, Netherlands.

Slichter, C. S. (1899), Theoretical investigation of the motion of ground waters, U.S. Geol. Surv. Annu. Rep., 19(2), 295-384.

Theis, C. V. (1935), The relation between the lowering of the piezometric surface and the rate and duration of discharge of a well using groundwater storage, Eos Trans. AGU, 2, 519.

Thiem, G. (1906), Hydrologische Methoden, 56 pp., Gephardt, Leipzig, Germany.

Tóth, J. (1963), A theoretical analysis of groundwater flow in small drainage basins, J. Geophys. Res., 68, 4795-4812.

P. Bobeck, Geotechnical Translations, P.O. Box 161391, Austin, TX 78716, USA.

R. W. Ritzi Jr., Department of Earth and Environmental Sciences, Wright State University, Dayton, OH 45430, USA. (robert.ritzi@wright.edu) 